\title{
Hyperthermic intraperitoneal chemotherapy in ovarian cancer: Qui Bono?
}

\author{
John Spiliotis \\ European Interbalkan Medical Center, Thessaloniki, Greece \\ Correspondence to: John Spiliotis. European Interbalkan Medical Center, Thessaloniki, Greece. Email: jspil@hotmail.gr.
}

\begin{abstract}
Ovarian cancer is a major cause of cancer related-death in women around the world. Recent statistics on the worldwide cancer burden by the International Agency for the research on Cancer revealed ovarian cancer being both the eighth most frequent malignancy in the west countries. Peritoneal metastasis from ovarian cancer is a major challenge in the clinical management. Despite the evidence of the benefit of Intraperitoneal Chemotherapy in ovarian cancer with peritoneal deposits it has not been widely adopted, mainly due to logistical difficulties and less to the logoregional morbidity as pain. The role of hyperthermic intraperitoneal chemotherapy (HIPEC) in patients during the end of cytoreductive surgery (CRS) is a more tolerable feasible method with potential advantages as drug distribution, combination with hyperthermia and application before tumor regrowth. The aim of this article is to investigate the potential benefits of HIPEC explains the rationale, data of major clinical trials meta-analyses and recent randomized trial are presented and explains the indications patient selection and the best time to applicate of this aggressive logo regional treatment.
\end{abstract}

Keywords: Cytoreductive surgery (CRS); hyperthermic intraperitoneal chemotherapy (HIPEC); ovarian cancer

Submitted Feb 10, 2020. Accepted for publication Jul 08, 2020.

doi: 10.21037/atm-20-1486

View this article at: http://dx.doi.org/10.21037/atm-20-1486

\section{Introduction}

Ovarian cancer remains a lethal condition among the women with gynecological tumors and the mortality rate will rise significantly by the year 2040 for different reasons (1). Cytoreductive surgery (CRS) and systemic chemotherapy by definition is the gold standard of treatment since the middle-90's (2).

Dissemination and implantation is the two most common routes of metastasis of peritoneum spread and the third route to lymph nodes or liver or lungs remains the hematogenous spread (3).

Intraperitoneal chemotherapy could reduce plasma toxicity compared with intravenous administration and increase the effect upon heating $(4,5)$.

Investigators world wide have explored the role of HIPEC combined with aggressive CRS with controversial results and lack of well designed prospective randomized trials.
On the other hand in the era of new drugs targeted therapies and immunotherapy the method demands strict criteria for application. The aim of this article is to focuses in this field with base evidence indications.

\section{Hyperthermic intraperitoneal chemotherapy (HIPEC)}

HIPEC is the delivery of intraperitoneal chemotherapy under high temperature of the drugs solution after aggressive CRS. It is a well known procedure in the last 30 years with controversial results in different gastro intestinal tumors (6).

The main debate is the different approaches of HIPEC, from different groups are the drugs, the style (open $v s$. closed) and the different time period of intraperitoneal chemotherapy (60 vs. 90 vs. $120 \mathrm{~min}$ ) and also the significantly more toxic effects concerning morbidity and mortality which are warning the academic community to 
remain skepticism about the implementation of the method in the arsenal of therapeutic management $(7,8)$.

Until the middle of recent decade the majority of ovarian cancer centers using the controversial systemic chemotherapy in the management of relapse or primary advance ovarian cancer (9). In 2015 a first randomized trial from Greece with some bias concerning the randomization approach investigating the role of HIPEC in "relapse" ovarian cancer with some excellent, a ray of hope, results concerning the OS (10).

Three years later van Driel et al. reported a benefit in survival with the use of HIPEC at interval debulking as upfront setting (11). At the same time a study from Korea, Lim et al. showed no benefit from HIPEC in the similar group of patients (12).

Many discussions are rising concerning the methodology of Driels study about patient selection, the role and the precision of cytoreduction in the 10 participating centers.

There was also an imbalance regarding the randomization, the toxicities and the adverse effects of neoadjuvant chemotherapy.

In conclusion in HIPEC group we observed more toxic effects and longer hospitalization and maybe worse quality of life (for example: stoma formation $72 \%$ in HIPEC group vs. $43 \%$ in non HIPEC group) (13).

As a result, the van Driel study should not drive changes in clinical practice in ovarian cancer and remains under investigation $(14,15)$.

In late 80 s a phase I trial study exams the pharmacological advantage of intraperitoneal normothermic chemotherapy (IP) by maintaining the drugs at higher concentration in the peritoneal spaced due to the lower peritoneal permeability $(16,17)$. And this permeability increases from 3 to $5 \mathrm{~mm}$ when the temperature of the solution achieves the 42.5 to 43 grade of Celsius and also has been described that this pharmacokinetic advantage of i.p chemo is particularly evident in smaller lesions and avascular tumors $(18,19)$.

All this data catching the attention of clinical oncologic society and in 2006 as a result of GOG172 a clinical alert was made available (20-22).

This study demonstrates that the combination of IP + IV chemotherapy versus only IV improves the progression free survival (PFS) by 5 months in the IP arm and the overall survival (OS) by nearly 16 months (22).

In practice the GOG 172 remains limited due to problems of intraperitoneal administration every week (day 2 and day 8 of the cycle) and the locally adverse effects (abdominal pain, mobilization of intraabdominal catheter, adhesion formation) and the evidence that after 2 or 3 cycles the fluid distribution is not impeded by different causes (23).

Another question which arises in GOG 172 study is the completeness of cytoreductive, which in this study remains optimal debulking $<1 \mathrm{~cm}$. This residual disease is huge as it is compared with $\mathrm{CCO}$ cytoreduction with no evidence of residual disease or $\mathrm{CC}$, that means less $0.25 \mathrm{~mm}$ (16,24-26).

The conclusion is that IP chemo therapy, either with local difficulties, improves OS and PFS in well selected patients after meticulous cytoreduction in order to eliminate all the visible disease $(16,26)$.

The most important thing is to standardize exactly the drugs and the dose and also the use of targeted therapies at the same time $(27,28)$. The main benefit and biological advantage remain the less toxicities less than iv chemotherapy and also the main logoregional effect in the peritoneal metastasis especially from ovarian tumors. Remains under question the consensus acceptance and demands main efforts from medical oncologist to accept this procedure.

\section{CRS}

The principles of CRS is to eliminate of all visible disease by surgical resection and includes peritonectomy procedures and organ sparing resections (29).

The most ideal procedure is to perform through a large midline laparotomy incision, but recently some groups especially in low peritoneal cancer index patients (PCI) are performed laparoscopically.

Diaphragmatic areas, liver Glisson capsule and falciform ligament is taken.

The PCI standardizes the initial tumor volume separating the abdominal cavity into 13 regions (Figure 1) (30). Maximal cytoreduction is a critical point of view especially in ovarian cancer patients concerning the OS and the residual disease after the initial operation remains the most important prognostic factor, together with tumor biology for the final outcome (6).

After the initial exploration to rule out the solid organ metastasis we procced with peritonectomies and resection of all sites of diseases. Most important think is to advocate the standard resection of the great omentum nearly to the splenic hilum and the lesser omentum. Cholecystectomy, appendicectomy and total hysterectomy with bilateral salpingo-oophorectomy are also the next steps concerning 

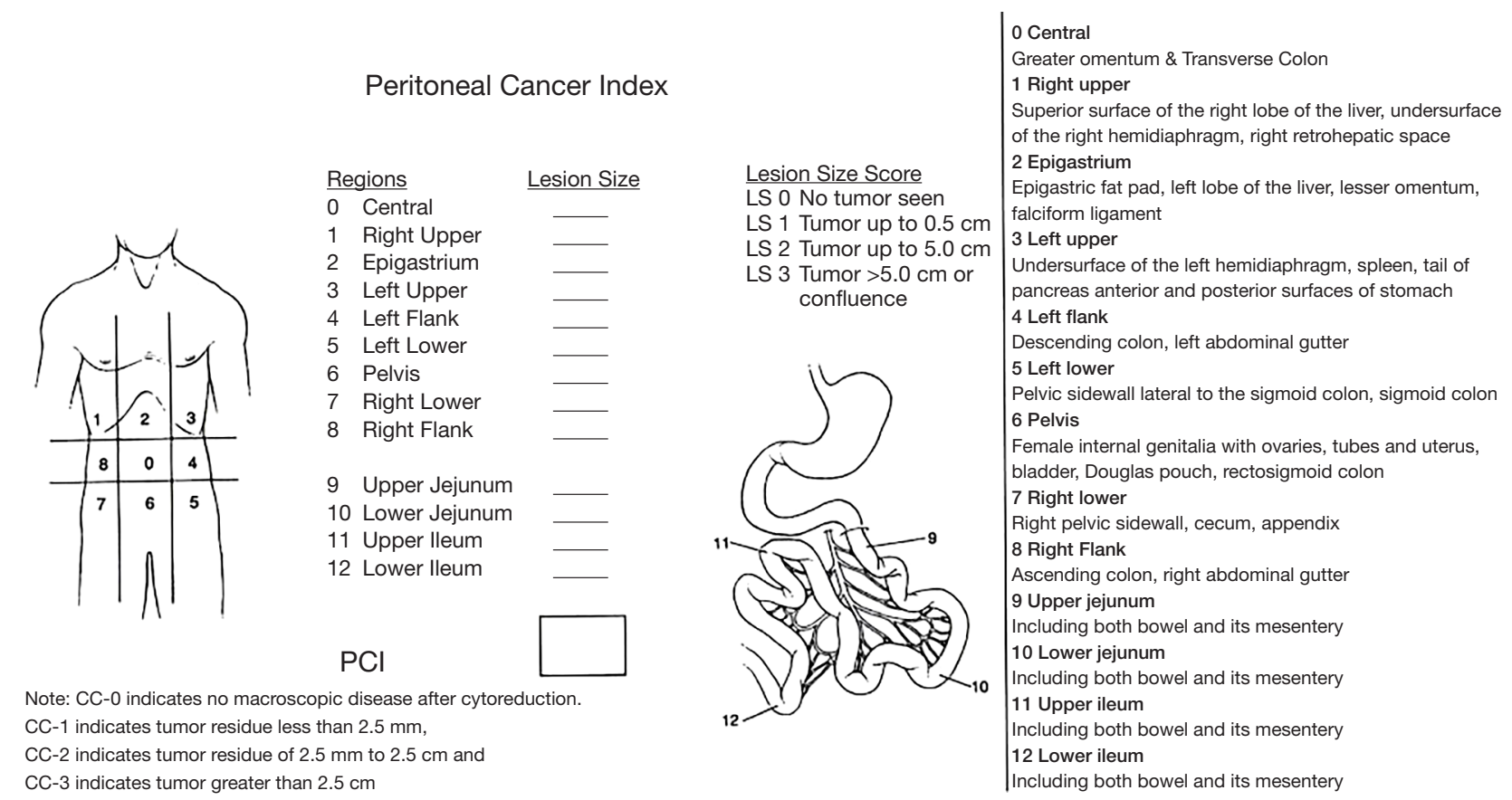

Figure 1 Peritoneal cancer index.

Table 1 Trials in upfront setting

\begin{tabular}{|c|c|c|c|}
\hline Study & Cohorts & Drugs & Results \\
\hline \multirow{3}{*}{$\begin{array}{l}\text { Ansaloni } \\
2012(33)\end{array}$} & Open prospective & Cisplatin $100 \mathrm{mgr} / \mathrm{m}^{2}$ & \multirow[t]{3}{*}{ No different survival } \\
\hline & Randomized II & Paclitaxel 175 mgr $/ \mathrm{m}^{2}$ & \\
\hline & Primary versus recurrent & Doxorubicine $25 \mathrm{mgr} / \mathrm{m}^{2} 90 \mathrm{~min} 41$. & \\
\hline \multirow{2}{*}{$\begin{array}{l}\operatorname{Lim} 2017 \\
(12)\end{array}$} & Randomized III & \multirow[t]{2}{*}{ Cisplatin $75 \mathrm{mgr} / \mathrm{m} 290 \min 41.5^{\circ} \mathrm{C}$} & \multirow{2}{*}{$\begin{array}{l}\text { 5-year survival, HIPEC 51\%, } \\
\text { control } 49.4 \% \text { NS }\end{array}$} \\
\hline & CRS + Syst. Chemotherapy & & \\
\hline \multirow{2}{*}{$\begin{array}{l}\text { van Driel } \\
2018(11)\end{array}$} & Neoadjchem 3 cycles + CRS + Hipec + Syst. Chem & \multirow[t]{2}{*}{ Cisplatin $100 \mathrm{mgr} / \mathrm{m} 290 \mathrm{~min} 40^{\circ} \mathrm{C}$} & Median survival, HIPEC \\
\hline & versus Neoadjchem 3 cycles + CRS + Syst. Chem & & $45.7 \mathrm{~m}$, control $33.9 \mathrm{~m}$ \\
\hline
\end{tabular}

CRS, cytoreductive surgery; HIPEC, hyperthermic intraperitoneal chemotherapy.

the cytoreduction.

Meticulous resection is important in the large implants in the smell bowel mesentery which sometimes demands small bowel resection. The diaphragmatic stripping is an important surgical route and the main reason of inappropriate cytoreductional the initial operation. It demands experience, surgical team and sometimes the place during or the end of the operation thoracic tubes to eliminate postoperative pleural infussions $(31,32)$.

\section{HIPEC as upfront treatment in primary ovarian cancer}

Multiple studies mainly retrospective and case control studies are published in the upfront setting. Table 1 summarized the most recent data.

In 2012, an Italian phase II prospective trial demonstrates improved outcome in well CRS patients with HIPEC and delayed recurrent time in $14.4 \mathrm{~m} \mathrm{(33).}$

In 2013, a French multicenter study evaluated 566 
patients, which includes 92 women in the upfront line setting a HIPEC. The median OS in this group was $35.4 \mathrm{~m}$ and in complete cytoreduction (CC0) the median survival was $41.5 \mathrm{~m}$ (34). In Spain at tertiary centers 52 patients received HIPEC in the upfront setting after CC0 in cytoreduction. Disease free survival was improved at 3 years (66\% vs. 18\%) $\mathrm{P}<0.01$ (35). Finally, Huo et al. in a recent meta-analysis showed an improvement in OS in the HIPEC arm when it compares with no-HIPEC arm (36).

The first more specifically, randomized, open-label phase III multicenter trial by van Driel et al. evaluated the role of HIPEC as a part of interval CRS in patients with stage III EOC (11).

The groups of patients are from 10 centers randomized, open-label was designed to assess the efficacy and safety of interval CRS + HIPEC. The 245 participants received neoadjuvant chemotherapy and had to have at least stable disease after 3 cycles of carboplatin and paclitaxel intravenously.

After surgery all patients received adjuvant chemotherapy with same regimen.

At a median follow-up of nearly 5 years, $50 \%$ of HIPEC group died versus $62 \%$ in no HIPEC group. The median OS was 45.7 versus $33.9 \mathrm{~m}(37-39)$.

Interesting data from Shimokawa et al. demonstrates the important role of first line chemotherapy in PFS and OS in advanced ovarian cancer (40).

Some cautions in the bias of this study concerning randomization, heterogeneity of the groups especially between the different centers, subgroups analyses and interactions of statistical tests produce a lack of consistency on the basis of different treatment effects $(41,42)$.

On the contrary in a study from Korea presented preliminary results of a randomized trial, neither median OS nor median RFS were different ( 54 vs. $51 \mathrm{~m} \mathrm{P}=0.4$ and 20 vs. $19 \mathrm{~m} \mathrm{P=0.1)}$ and among the patients from the neoadjuvant subgroup who were randomized to receive either surgery plus HIPEC or no HIPEC for the management of EOC of stage III and IV (43).

Interestingly the neoadjuvant group showed a trend of improved survival in favour of HIPEC group after $30 \mathrm{~m}$ of OS and $20 \mathrm{~m}$ of RFS which necessitates further long term observation.

Concerning complications, the HIPEC group was found with significantly increases rates of anemia and creatinine elevation compared to control group and the dose of the IP cisplatin was de-escaled to $75 \mathrm{mgr}$ which was administered for $90 \mathrm{~min}$ at $41.5^{\circ} \mathrm{C}$.
The questions remain unanswered when using HIPEC in primary treatment ovarian cancer. It is obvious that further well-designed prospective randomized trials are warranted to describe the role of HIPEC application in the management of primary EOC. It appears that using it at interval cytoreduction holds the most promise and the latest NCCN guidelines supports this approach. The NCCN recommends that all women undergoing surgery for ovarian cancer should be counseled for combined iv and ip chemotherapy administration preoperatively. Finally, the fact that elderly and medically infirm patients experience problematic tolerance to ip chemotherapy is reiterated $(44,45)$.

Further questions regarding the most appropriate drug, dosing, time and temperature also exist. For instance, the CHORINE study the interim analysis of the other ongoing protocols demonstrates promising results.

\section{HIPEC in relapse disease}

Residual ovarian cancer remains a difficult problem in the management of EOC, with the recurrence rates arises to $50-70 \% 3$ years after initial treatment.

Among other factors completeness of primary/internal debulking is also affecting the patient risk of "relapse".

Recent study from our group demonstrates the incidence of residual disease in $70 \%$ of cases (46). By definition in our study, the main sites of residual disease are, if we observed deposits in remain great omentum, liver rounge ligament, gallbladder and vaginal stump and recurrent disease included small bowel, mesenterium, pelvic floor, diaphragm (31).

The most important finding is the survival rates between residual and recurrent disease. Median survival rates in residual disease HIPEC group was 38 versus $26 \mathrm{~m}$ in recurrent HIPEC group (46).

\section{HIPEC in recurrent disease}

The use of HIPEC for the secondary management of relapse due to advanced EOC has been more extensively investigated. The majority of studies are retrospective small trials, evaluating small number of patients (Table 2).

A phase I trial from Zivanovic et al. evaluated the dose of cisplatin (maximum tolerated) for HIPEC and a phase II trial is currently under investigation (47).

Another paper from France in recurrent chemosensitive and chemoresistant EOC patients demonstrates improves of survival in lower PCI $<8$ and CC0 score. The results also 
Table 2 HIPEC in relapse ovarian cancer

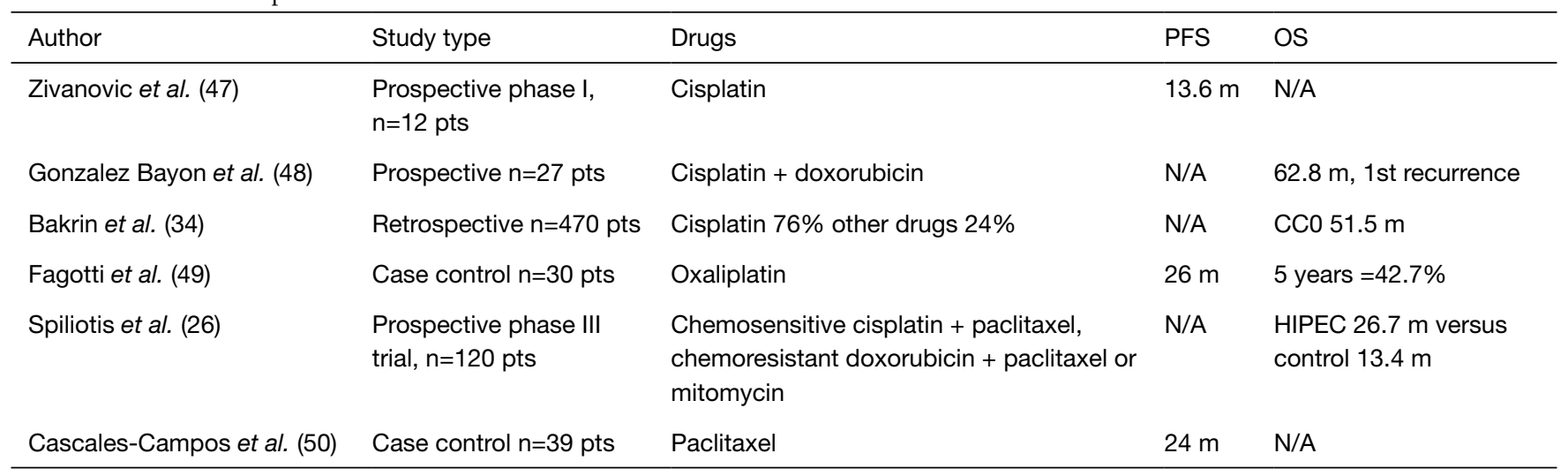

Last decade studies on role of HIPEC in recurrent disease. HIPEC, hyperthermic intraperitoneal chemotherapy; PFS, progression free survival; OS, overall survival.

demonstrate not significant difference between platinum sensitive or resistant tumors (34). The last observation demands and need more available data (51).

A Spain study evaluates the role of HIPEC in primary and secondary recurrent disease from EOC and demonstrates an improvement of OS in both groups and also in both CC0 and CC1 cytoreduction groups (48). The main question concerning the role of HIPEC in this study is that the survival is similar with other studies without HIPEC but treated with secondary cytoreduction only $(52,53)$.

Cascales-Campos et al. (50) in 2015 evaluate the CRS solely versus CRS plus HIPEC in platinum-sensitive EOC. The results demonstrate same PFS $(22$ vs. $21 \mathrm{~m})$ in favor of CRS alone. The only explication for this result is that in the 39 patients of HIPEC group the mean PCI score is significantly higher. Some investigators suggest also a bias in the choice of paxcitaxel as HIPEC regimen which it may not be effective for use (50).

Fagotti et al. (49) in a case control study with 3 arms CRS + IV chemo, (13 pts) IV chemotherapy alone (24 pts) and CRS + HIPEC (30 pts). The results demonstrate similar RFS and only a minimal pattern of recurrence with HIPEC group to achieve a longer secondary PFS after initial treatment (49).

The first RTC in the field was published by Spiliotis et al. (26) evaluated the role of HIPEC at first recurrence and was highly criticized due to methodological issue.

The authors included 120 patients with advanced stage EOC (> IIIc) who had disease recurrence and were randomized to either receive CRS plus HIPEC followed by systemic chemotherapy or CRS with systemic chemotherapy alone.

The regimens used for IP administration were as follows: $100 \mathrm{mgr} / \mathrm{m}^{2}$ cisplatin and $175 \mathrm{mgr} / \mathrm{m}^{2}$ paxcitaxel for platinum sensitive disease and whereas for platinum resistant disease $35 \mathrm{mgr} / \mathrm{m}^{2}$ doxorubicin and $175 \mathrm{mgr} / \mathrm{m}^{2}$ paxcitaxel or $15 \mathrm{mgr} / \mathrm{m}^{2}$ mitomycin for $60 \mathrm{~min}$ at $42.5^{\circ} \mathrm{C}$ in both groups. A significant improved in the mean OS in the 3 year overall was noted in favour of HIPEC group in both platinum sensitive or platinum resistant women (26).

Additionally in another study by Spiliotis et al. (46) the authors tried to clarify whether there is difference in survival who received CRS plus HIPEC as secondary management of residual or recurrent disease after primary surgery in favour of residual disease (38 vs. $26 \mathrm{~m})$ (46).

The aforementioned outcomes indicate the significance of the complete cytoreduction in the primary management of advanced EOC, which was further enhanced by the addition of HIPEC.

\section{Future directions}

The most important issue at this moment is what is the role of HIPEC and the timing of administration in the management of EOC.

In our group recently we exam the data from our data base in 230 women with advance ovarian cancer. There are 30 upfront procedures with a median survival of $32 \mathrm{~m}, 60$ women with Neo-adjuvant chemotherapy with intermined cytoreduction with $30 \mathrm{~m}$ median survival and 140 cases with "relapse disease" (recurrent or residual) with median survival of $38 \mathrm{~m}$ far residual disease compared to $23.8 \mathrm{~m}$ for recurrent disease. 
Another question is what is the role of systemic chemotherapy in relapse disease.

There is some evidence that the use of second line systemic chemotherapy in relapse ovarian cancer before the CRS + HIPEC may offers a survival benefit in PFS and OS as compare with CRS + HIPEC alone (46 versus $31 \mathrm{~m}$ $\mathrm{P}=0.013)$ (46).

The main debate especially in multidisciplinary tumor conferences is what kind of IP chemotherapy would be recommended for a woman if she was diagnosed with advanced ovarian cancer. There are two attitudes: one with normothermic IP based on the results of GOG172 with a median global survival of $65.2 \mathrm{~m}$ but with possibilities of successfully finish the treatment schedule very low $42 \%$. On the other hand, the choice of HIPEC which with acceptable morbidity and mortality rates with acceptable risk the 5 years survival rates higher that $60 \%$ (54). The fact that although GOG 172 showed worse toxicity in the ip group, the most recent GOG 252 study demonstrated that the overall rates of toxicities and discontinuation among iv and ip chemotherapy arms were comparable (28).

A recent article from Fotopoulou et al. (55) arises the question concerning HIPEC: is a hope of hype in the fight against advanced ovarian cancer? The response from the authors of this article is that: Publicly available evidence addressing the value of HIPEC in EOC is rather inconclusive, revealing contradictory and inconsistent results while some studies even report harm to the patients from a higher morbidity. On this ground we cannot recommend the implementation and use of HIPEC outside of a randomized clinical trial setting (55).

So the question concerning our review is: is the right time to include HIPEC as a standard of care in ovarian cancer management? Although there is as strong rationale for the implementation of HIPEC in ovarian cancer treatment scientifically sound data from randomized clinical trial are coming. Recently DESKTOP III confirmed the role of optimal cytoreduction in the recurrent disease. We reached the same conclusion by the HIPEC trials as well (56). Another important observation is that the result of HIPEC is related to PCI, therefore the possibility to achieve optimal cytoreduction (57). The results from the Japanese iPocc trial are eagerly expected (NCT01506856; Intraperitoneal Therapy For Ovarian Cancer With Carboplatin Trial). This is a randomized phase II/III trial of iv weekly paclitaxel plus iv carboplatin once every 3 weeks versus iv weekly paclitaxel plus ip carboplatin once every 3 weeks in patients with epithelial ovarian cancer.
The study attempts to isolate the effects of ip carboplatin; nevertheless, it enrolls few Caucasians, which would raise serious concerns.

The two main questions emerge for further research is when is the best setting to perform HIPEC and is it high time for inclusion of HIPEC in standard clinical practice. The rationale for HIPEC as a part of a multi-model treatment in women with advanced ovarian cancer is strong. In combination with CRS this type of aggressive locoregional therapy has the potential to cure patients given that hyperthermia enhances tumor penetration and the cytotoxic effects of chemotherapy. HIPEC does not increase the mortality and morbidity compared to CRS alone. This type of treatment should be offered at experienced centers by well-trained multidisciplinary groups after meticulous patient selection (58).

\section{Acknowledgments}

I wish to express my thanks to Samara Maria for her secretarial assistance.

Funding: None.

\section{Footnote}

Provenance and Peer Review: This article was commissioned by the Guest Editors (Stergios Boussios and Nicholas Pavlidis) for the series "Ovarian Cancer: State of the Art and Perspectives of Clinical Research" published in Annals of Translational Medicine. The article was sent for external peer review organized by the Guest Editors and the editorial office.

Conflicts of Interest: The author has completed the ICMJE uniform disclosure form (available at http://dx.doi. org/10.21037/atm-20-1486). The series "Ovarian Cancer: State of the Art and Perspectives of Clinical Research" was commissioned by the editorial office without any funding or sponsorship. The author has no other conflicts of interest to declare.

Ethical Statement: The author is accountable for all aspects of the work in ensuring that questions related to the accuracy or integrity of any part of the work are appropriately investigated and resolved.

Open Access Statement: This is an Open Access article distributed in accordance with the Creative Commons 
Attribution-NonCommercial-NoDerivs 4.0 International License (CC BY-NC-ND 4.0), which permits the noncommercial replication and distribution of the article with the strict proviso that no changes or edits are made and the original work is properly cited (including links to both the formal publication through the relevant DOI and the license). See: https://creativecommons.org/licenses/by-nc-nd/4.0/.

\section{References}

1. Ferlay J, Colombet M, Soerjomataram I, et al. Estimateing the Global Cancer Incidence and Mortality in 2018: GLOBOCAN Sources and Methods. Int J Cancer 2019;144:1941-53.

2. Rufián S, Munoz-Casares FC, Briceno J, et al. Radical surgery-peritonectomy and intraoperative intraperitoneal chemotherapy for the treatment of peritoneal carcinomatosis in recurrent or primary ovarian cancer. J Surg Oncol 2006;94:316-24.

3. Stamou KM, Karakozis S, Sugarbaker PH. Total abdominal colectomy, pelvic peritonectomy and endileostomy for the surgical palliation of mucinous peritoneal carcinomatosis from non-gynecologic cancer. J Surg Oncol 2003;83:197-203.

4. Bakrin N, Classe JM, Pomel C, et al. Hyperthermic intraperitoneal chemotherapy (HIPEC) in ovarian cancer. J Visc Surg 2014;151:347-53.

5. Sugarbaker PH. Surgical responsibilities in the management of peritoneal carcinomatosis. J Surg Oncol 2010;101:713-24.

6. Verwaal VJ, Van Ruth S, de Bree E, et al. Randomized trial of cytoreduction and hyperthermic intraperitoneal chemotherapy versus systemic chemotherapy and palliative surgery in patients with peritoneal carcinomatosis of colorectal cancer. J Clin Oncol 2003;21:3737-43.

7. Harter P, Du Bois A, Mahner S, et al. Statement of the AGO KommissionOvar, AGO Study Group, NOGGO, AGO Austria and AGO Switzerland Regarding the Use of Hyperthermic Intraperitoneal Chemotherapy (HIPEC) in Ovarian Cancer. Geburtshilfe Frauenheilkd2016;76:147-9.

8. Quenet F, Elias D, Roca L. A UNICANCER phase III trial of hyperthermic intra-peritoneal chemotherapy (HIPEC) for colorectal peritoneal carcinomatosis (PC): PRODIGE 7. J Clin Oncol 2018;36:abstr LBA3503.

9. Spiliotis J, Halkia E, de Bree E.Treatment of peritoneal surface malignancies with hyperthermic intraperitoneal chemotherapy-current perspectives. Curr Oncol 2016;23:e266-75.
10. Harter P, Reuss A, Sehouli J, et al. Brief report about the role of hyperthermic intraperitoneal chemotherapy in a prospective randomized phase 3 study in recurrent ovarian cancer from Spiliotis et al. Int J Gynecol Cancer 2017:27:246-7.

11. van Driel WJ, Koole SN, Sikorska K, et al.Hyperthermic intraperitoneal chemotherapy in ovarian cancer. $\mathrm{N}$ Engl J Med 2018;378:230-40.

12. Lim MC, Chang SJ, Yoo HJ, et al. Randomized trial of hyperthermic intraperitoneal chemotherapy (HIPEC) in women with primary advanced peritoneal, ovarian, and tubal cancer. J Clin Oncol 2017;35:abstr 5520.

13. Vergote I, Chiva L, du Bois A.Hyperthermic intraperitoneal chemotherapy in ovarian cancer. $\mathrm{N}$ Engl J Med 2018;378:1362-3.

14. Spriggs DR, Zivanovic O. Ovarian cancer treatment: Are we getting warmer? N Engl J Med 2018;378:293-4.

15. Colombo N, Sessa C, du Bois A, et al. ESMO-ESGO Consensus Conference on Ovarian Cancer: pathology and molecular biology, early and advanced stages, borderline ovarian tumours and recurrent disease. Ann Oncol 2019;30:672-705.

16. Dedrick RL, Myers CE, Bungay PM, et al. Pharmacokinetic rationale for peritoneal drug administration in the treatment of ovarian cancer. Cancer Treat Rep 1978;62:1-11.

17. Dedrick RL. Theoretical and experimental bases of intraperitoneal chemotherapy. Semin Oncol 1985;12:1-6.

18. Balthasar JP, Fung HL. Pharmacokinetic and Pharmacodymanic Optimization of Intraperitoneal Chemotherapy. Life Sci 1996;58:535-43.

19. Spratt JS, Adcock RA, Muskovin M, et al. Clinical delivery system for intraperitoneal hyperthermic chemotherapy. Cancer Res 1980;40:256-60.

20. Casper ES, Kelsen DP, Alcock NW, et al. Ip cisplatin in patients with malignant ascites: Pharmacokinetic evaluation and comparison with the iv route. Cancer Treat Rep 1983;67:235-8.

21. Zimm S, Cleary SM, Lucas WE, et al. Phase I/ pharmacokinetic study of intraperitoneal cisplatin and etoposide. Cancer Res 1987;47:1712-6.

22. Armstrong DK, Bundy B, Wenzel L, et al. Gynecologic Oncology, G. Intraperitoneal cisplatin and paclitaxel in ovarian cancer. N Engl J Med 2006;354:34-43.

23. Cowan RA, O'Cearbhaill RE, Zivanovic O, et al. Current status and future prospects of hyperthermic intraoperative intraperitoneal chemotherapy (HIPEC) clinical trials in ovarian cancer. Int J Hyperthermia 2017;33:548-53. 
24. Los G, Mutsaers PH, van der Vijgh WJ, et al. Direct diffusion of cis-diamminedichloroplatinum (II) in intraperitoneal rat tumors after intraperitoneal chemotherapy: a comparison with systemic chemotherapy. Cancer Res 1989;49:3380-4.

25. Ansaloni L, Coccolini F, Morosi L, et al. Pharmacokinetics of concomitant cisplatin and paclitaxel administered by hyperthermic intraperitoneal chemotherapy to patients with peritoneal carcinomatosis from epithelial ovarian cancer. Br J Cancer 2015;112:306-12.

26. Spiliotis J, Halkia E, Lianos E, et al. Cytoreductive surgery and Hipec in recurrent epithelial ovarian cancer: A prospective randomized Phase III study. Ann Surg Oncol 2015;22:1570-75.

27. Wright AA, Cronin A, Milne DE, et al. Use and effectiveness of intraperitoneal chemotherapy for treatment of ovarian cancer. J Clin Oncol 2015;33:2841-7.

28. Walker JL, Brady MF, Wenzel L, et al. Randomized trial of intravenous versus intraperitoneal chemotherapy plus bevacizumab in advanced ovarian carcinoma: an NRG Oncology/Gynecologic Oncology Group study. J Clin Oncol 2019;37:1380-90.

29. McQuellon RP, Loggie BW, Lehman AB, et al. Longterm survivorship and quality of life after cytoreductive surgery plus intraperitoneal hyperthermic chemotherapy for peritoneal carcinomatosis. Ann Surg Oncol 2003;10:155-62.

30. Jacquet P, Sugarbaker PH. Clinical research methodologies in diagnosis and staging of patients with peritoneal carcinomatosis. Cancer Treat Res 1996;82:359-74.

31. Halkia E, Kopanakis N, Valavanis C et al. Is cholecystectomy and removal of the round ligament of the liver a necessary step in cytoreductive surgery and HIPEC for peritoneal carcinomatosis. Ann Ital Chir 2015;86:323-6.

32. Halkia E, Efstathiou E, Spiliotis J, et al. Management of diaphragmatic peritoneal carcinomatosis. Surgical anatomy quidelines and results. J BUON 2014;19:29-33.

33. Ansaloni L, Agnoletti V, Amadori A, et al. Evaluation of extensive cytoreductive surgery and hyperthermic intraperitoneal chemotherapy (HIPEC) in patients with advanced epithelial ovarian cancer. Int J Gynecol Cancer 2012;22:778-85.

34. Bakrin N, Bereder JM, Decullier E, et al. Peritoneal carcinomatosis treated with cytoreductive surgery and Hyperthermic Intraperitoneal Chemotherapy (HIPEC) for advanced ovarian carcinoma: A French multicentre retrospective cohort study of 566 patients. Eur J Surg
Oncol 2013;39:1435-43.

35. Cascales-Campos PA, Gil J, Gil E, et al. Treatment of microscopic disease with hyperthermic intraoperative intraperitoneal chemotherapy after complete cytoreduction improves disease-free survival in patients with stage IIIC/ IV ovarian cancer. Ann Surg Oncol 2014;21:2383-9.

36. HuoYR, Richards A, Liauw W, etal. Hyperthermic intraperitoneal chemotherapy (HIPEC) and cytoreductive surgery (CRS) in ovarian cancer: A systematic review and meta-analysis. Eur J Surg Oncol 2015;41:1578-89.

37. Rettenmaier MA, Mendivil AA, Abaid LN, et al. Consolidation hyperthermic intraperitoneal chemotherapy and maintenance chemotherapy following laparoscopic cytoreductive surgery in the treatment of ovarian carcinoma. Int J Hyperthermia 2015;31:8-14.

38. du Bois A, Quinn M, Thigpen T, et al. 2004 consensus statements on the management of ovarian cancer: final document of the 3rd International Gynecologic Cancer Intergroup Ovarian Cancer Consensus Conference (GCIG OCCC 2004). Ann Oncol 2005;16:17-12.

39. Coleman RL, Spirtos N, Enserro D, et al. Secondary Surgical Cytoreduction for Recurrent Ovarian Cancer. N Engl J Med 2019;381:1929-39.

40. Shimokawa M, Ohki M, Kaku T. Correlation of progression-free and post-progression survival with overall survival in phase III trials of first-line chemotherapy for advanced epithelial ovarian cancer. Eur J Gynaecol Oncol 2015;36:370-5.

41. Wang R, Lagakos SW, Ware JH, et al. Statistics in medicine-reporting of subgroup analyses in clinical trials. N Engl J Med 2007;357:2189-94.

42. Van Drial WJ, Koole SN, Sonke GS. Hyperthermic intraperitoneal chemotherapy in ovarian cancer. J Engl J Med 2018;378:1363-4.

43. Lim MC, Chang SJ, Yoo HJ, et al. Randomized trial of hyperthermic intraperitoneal chemotherapy (HIPEC) in women with primary advanced peritoneal ovarian and tubal cancer. J Clin Oncol 2017;35:abstr 5520.

44. Armstrong DK, Alvarez RD, Bakkum-Gamez JN, et al. NCCN Guidelines Insights: Ovarian Cancer, Version 1.2019. J Natl Compr Canc Netw 2019;17:896-909.

45. National Comprehensive Cancer Network. Ovarian Cancer Including Fallopian Tube Cancer and Primary Peritoneal Cancer, Version 1.2020, March 112020.

46. Iavazzo C, Fotiou A, Tsiatas M, et al. Survey on the current gynaecological approach of ovarian cancer patients: The utility of HIPEC. Pleura Peritoneum 2020;5:20190029.

47. Zivanovic O, Abramian A, Kullmann M. HIPEC ROC I: 
A phase I study of cisplatin administered as hyperthermic intraoperative intraperitoneal chemoperfusion followed by postoperative intravenous platinum-based chemotherapy in patients with platinum-sensitive recurrent epithelial ovarian cancer. Int J Cancer 2015;136:699-708.

48. Gonzalez Bayon L, Steiner MA, Vasquez Jimenez W, et al. Cytoreductive surgery and hyperthermic intraperitoneal chemotherapy for the treatment of advanced epithelial ovarian carcinoma: Upfront therapy, at first recurrence, or later? Eur J Surg Oncol 2013;39:1109-15.

49. Fagotti A, Costantini B, Petrillo M, et al. Cytoreductive surgery plus HIPEC in platinum-sensitive recurrent ovarian cancer patients: A case-control study on survival in patients with two year follow-up. Gynecol Oncol 2012;127:502-5.

50. Cascales-Campos PA, Gil J, Feliciangeli E, et al. The role of hyperthermic intraperitoneal chemotherapy using paclitaxel in platinum-sensitive recurrent epithelial ovarian cancer patients with microscopic residual disease after cytoreduction. Ann Surg Oncol 2015;22:987-93.

51. Di Giorgio A, De Iaco P, De Simone M, et al. Cytoreduction (Peritonectomy Procedures) Combined with Hyperthermic Intraperitoneal Chemotherapy (HIPEC) in Advanced Ovarian Cancer: Retrospective Italian Multicenter Observational Study of 511 Cases. Ann

Cite this article as: Spiliotis J. Hyperthermic intraperitoneal chemotherapy in ovarian cancer: Qui Bono? Ann Transl Med 2020;8(24):1708. doi: 10.21037/atm-20-1486
Surg Oncol 2017;24:914-22.

52. Benedetti Panici P, De Vivo A, Bellati F, et al. Secondary cytoreductive surgery in patients with platinum-sensitive recurrent ovarian cancer. Ann Surg Oncol 2007;14:1136-42.

53. Tian WJ, Jiang R, Cheng X, et al. Surgery in recurrent epithelial ovarian cancer: Benefits on Survival for patients with residual disease of $0.1-1 \mathrm{~cm}$ after secondary cytoreduction. J Surg Oncol 2010;101:244-50.

54. Cascales Campos PA, Gil J, Munoz-Ramon P, et al. Hipec in Ovarian Cancer. Why is it Still the Ugly Duckling of Intraperitoneal Therapy? J Cancer Sci Ther 08:030. doi: 10.4172/1948-5956.1000383.

55. Fotopoulou C, Sehouli J, Mahner S, et al. HIPEC: HOPE or HYPE in the fight against advanced ovarian cancer?Ann Oncol 2018;29:1610-3.

56. Pignata S, Pisano C, Di Napoli M, et al. Treatment of Recurrent Epithelial Ovarian Cancer. Cancer 2019;125:4609-15.

57. Jewell A, Mc Mahon M, Khabele D. Heated Intraperitoneal Chemotherapy in the Management of Advanced Ovarian Cancer. Cancers 2018;10:296.

58. Riggs MJ, Pandalai PK, Kim J, et al. Hyperthermic Intraperitoneal Chemotherapy in Ovarian Cancer. Diagnostics 2020;10:43. 